\title{
Modafinil Blocks Reinstatement of Extinguished Opiate-Seeking in Rats: Mediation by a Glutamate Mechanism
}

\author{
Pouya Tahsili-Fahadan', Gregory V Carr ${ }^{2}$, Glenda C Harris ${ }^{3}$ and Gary Aston-Jones*,' \\ 'Laboratory of Neuromodulation and Behavior, Department of Neurosciences, Medical University of South Carolina, Charleston, SC, USA; \\ ${ }^{2}$ Neuroscience Graduate Group, University of Pennsylvania, Philadelphia, PA, USA; ${ }^{3}$ Department of Psychiatry, University of Pennsylvania, \\ Philadelphia, PA, USA
}

\begin{abstract}
Opiate addiction is characterized by high rates of relapse even after long periods of abstinence, requiring new relapse-prevention treatments that do not have abuse potential. Recently, clinical studies suggested that the wake-promoting drug modafinil might decrease relapse in cocaine addicts. In addition, group II metabotropic glutamate receptors (mGlu2/3R) have been suggested as a new therapeutic target for drug addiction. Here, we investigated the ability of modafinil to prevent the acute morphine to promote reinstatement of extinguished preference for morphine, and the involvement of mGlu2/3Rs in this effect. Conditioned place preference (CPP) for morphine was induced in Sprague-Dawley rats, followed by extinction training. Preference for the morphine-paired side was reinstated following extinction by a morphine-priming injection. The results of our study showed that modafinil (300 mg/ $/ \mathrm{kg}$, i.p., but not $100 \mathrm{mg} / \mathrm{kg}$ ) 30 min before the morphine-priming injection blocked reinstatement of extinguished CPP. The anti-reinstatement effect of modafinil was completely prevented by pretreatment with the selective mGlu2/3 antagonist LY34I495. Additional experiments indicated that modafinil alone did not produce a preference, and that modafinil did not alter the expression of morphine CPP or the cueing properties of morphine either I or 14 days after morphine CPP conditioning. These data reveal a novel mechanism for modafinil actions, a role for $\mathrm{mGlu2/3}$ receptors in reinstatement of opiate-seeking, and a new therapeutic option to treat relapse in opiate addiction.

Neuropsychopharmacology (2010) 35, 2203-2210; doi:I0.1038/npp.2010.94; published online 14 July 2010
\end{abstract}

Keywords: modafinil; morphine; conditioned place preference; reinstatement; relapse; metabotropic glutamate receptors

\section{INTRODUCTION}

A high rate of relapse following abstinence remains the most challenging aspect of opiate addiction treatment. Available treatments for opiate addiction are of limited effectiveness and not devoid of side effects (Nutt and Lingford-Hughes, 2008; O'Brien, 1997), indicating the need for newer pharmacotherapies.

Modafinil (2-diphenylmethyl-sulfinyl-2 acetamide) is a wake-promoting agent approved for the treatment of narcolepsy, obstructive sleep apnea, and shift-work sleep disorders (Minzenberg and Carter, 2008). Recently, clinical trials have reported that modafinil may be effective in treating cocaine dependence. These results indicate that modafinil reduces cocaine self-administration, the subjective response to cocaine, and the number of relapse

\footnotetext{
*Correspondence: Dr G Aston-Jones, Laboratory of Neuromodulation and Behavior, Department of Neurosciences, Medical University of South Carolina, 403 BSB, 173 Ashley Avenue, Charleston, SC 29425, USA, Tel: + I 843792 6092; Fax: + I 843792 4423,

E-mail: astong@musc.edu

Received II January 20 I0; revised 9 May 20 I0; accepted I June 2010
}

incidents (Dackis et al, 2005; Hart et al, 2008; Malcolm et al, 2006). However, previous studies in animal models have failed to show an antirelapse effect of modafinil for stimulants. Modafinil failed to alter reinstatement and intravenous self-administration of cocaine (Deroche-Gamonet et al, 2002) and even led to reinstatement of cocaineconditioned place preference (CPP; Bernardi et al, 2009). In addition, the effects of modafinil on opiate-seeking have not been assessed either in human addicts or animal models. Here, we examined effectiveness of modafinil in preventing morphine-induced reinstatement of an extinguished morphine place preference.

Despite its clinical applications, the exact mechanism(s) and site(s) of action for modafinil effects on sleep/wake cycles or drug abuse remain unknown. Although modafinil was originally categorized as a psychostimulant, its structure, sites of action, as well as neurochemical and behavioral effects appear to be different from those of prototypical stimulants such as cocaine and amphetamine. The wake-promoting effects of modafinil have been attributed to increasing dopamine and norepinephrine release by directly bindings to their transporters; however, it has also been shown that high doses of modafinil can 
affect several other neurotransmitter pathways (that are also involved in addictive behaviors such as glutamate, GABA serotonin, and orexin) by unknown mechanisms (Minzenberg and Carter, 2008).

Group II metabotropic glutamate receptors (mGlu2/3Rs) have been suggested as a new therapeutic target for drug addiction (Markou, 2007). This idea stems in part from the observation that chronic drug exposure decreases basal glutamate levels, and that restoration of basal levels of glutamate, and subsequent activation of mGlu2/3Rs, blocks reinstatement of cocaine or opiate-seeking (Wong et al, 1999; Knackstedt and Kalivas, 2009). We hypothesized that the glutamate release caused by modafinil would stimulate mGlu2/3Rs, and in turn block the relapse to drug-seeking.

\section{MATERIALS AND METHODS}

\section{Subjects}

Male Sprague-Dawley rats (250-300 g; Harlan Labs and Charles River) were housed in pairs on a $12 \mathrm{~h}$ light/dark cycle (lights on at 0600 hours) in accordance with NIH guidelines with food and water were present ad libitum. All trials were carried out in the light phase (0900-1500 hours). Rats were allowed at least 6 days to acclimatize to the laboratory environment before testing began. During this period rats were handled, weighed, and habituated to the drug administration procedure by receiving at least three intraperitoneal (i.p.) injections of saline. Different groups of naive rats were used for the different experiments. All protocols were approved by the Institutional Animal Care and Use Committees of the University of Pennsylvania and Medical University of South Carolina. All possible measures were undertaken to minimize the number of rats used and suffering of animals.

\section{Drugs}

Morphine sulfate (NIDA, Baltimore, MD; 8 and $16 \mathrm{mg} / \mathrm{kg}$ ) was dissolved in sterile $0.9 \%$ saline and administered in a volume of $1 \mathrm{ml} / \mathrm{kg}$. Modafinil, a gift from Cephalon (West Chester, PA), was freshly suspended in saline containing $0.5 \%$ Arabic gum so that doses were injected in a volume of $4 \mathrm{ml} / \mathrm{kg}$. The doses of modafinil used in this study were based on previous findings indicating that lower doses (Deroche-Gamonet et al, 2002) failed to affect reinstatement of drug-seeking, and that only a high dose $(300 \mathrm{mg} / \mathrm{kg})$ of modafinil increased striatal glutamate release (Ferraro et al, 1998). A selective antagonist of mGlu2/3Rs, LY341495 (Tocris), was dissolved in saline, and the $\mathrm{pH}$ was adjusted to $7.3( \pm 0.1)$ with $\mathrm{NaOH}$. The dose of the mGlu2/3R antagonist we used was based on previous studies (Moran et al, 2005). All drugs were administered i.p. and appropriate vehicle controls were performed for each experiment.

\section{Conditioned Place Preference and Reinstatement Procedures}

A CPP paradigm was used using a custom two-compartment apparatus identical to our previously published reports (Harris and Aston-Jones, 2003a,b; Harris et al, 2005). Visual and tactile cues were used to distinguish the two compartments: the inner walls of one compartment were black with a grid floor and the other compartment had vertical black and white striped walls with a mesh floor. The two compartments were equally preferred in nonconditioned animals. All sessions were conducted with the boxes contained in a dimly lit isolation box supplied with a continuous masking noise. On the first day (ie, preconditioning), each rat was placed separately into the apparatus for $15 \mathrm{~min}$, and was allowed free access to both compartments. The time spent in each compartment was recorded to determine any innate preference for either of the two compartments. After this test, the animals were grouped randomly. The conditioning phase consisted of six 30-min conditioning sessions held on 3 consecutive days (one session in the morning and one in the afternoon). On each session, rats were given injections of either drug (morphine $8 \mathrm{mg} / \mathrm{kg}$ or modafinil $300 \mathrm{mg} / \mathrm{kg}$ ) or the vehicles and were confined to the assigned compartment for $30 \mathrm{~min}$. Drug and vehicle sessions were alternated between the morning and afternoon sessions, so that rats given drug while in one chamber in the morning were given vehicle in the opposite chamber in the afternoon, and on subsequent days received vehicle in the morning and drug in the afternoon. The morning and afternoon injections were at least $5 \mathrm{~h}$ apart. The treatment compartment and order of presentation of drug and vehicle were counterbalanced across groups. On the test day (ie, fifth day of the procedure, denoted as the preference test; no preceding injections in the last $24 \mathrm{~h}$ ), the partition between compartments was removed and animals were given free access to both compartments for $15 \mathrm{~min}$.

Extinction consisted of two daily $15 \mathrm{~min}$ post-conditioning sessions without any injection, and was carried out from $24 \mathrm{~h}$ after the post-conditioning preference test and continued until the preference for the morphine-paired side decreased to $<75 \mathrm{~s}$ difference for four consecutive sessions. The reinstatement test $(15 \mathrm{~min})$ was conducted 24-h later with a priming injection of morphine $(8$ or $16 \mathrm{mg} /$ $\mathrm{kg}$ ) immediately before placing rats in the CPP apparatus with free access to both sides. The amount of time spent in each compartment and locomotor activity were recorded using eight pairs of photo beam detectors during the tests (MED Associates, East Fairfield, VT, USA).

\section{Experimental Design}

The experimental design is illustrated in Figure 1. In Experiment 1, we tested whether modafinil alone produced a CPP. During conditioning, animals received modafinil $(300 \mathrm{mg} / \mathrm{kg})$ or its vehicle $30 \mathrm{~min}$ before each $30 \mathrm{~min}$ conditioning session on alternate sessions. In Experiments 2 and 3, we investigated the effect of modafinil on morphine-primed reinstatement of CPP. For this, modafinil $(100$ or $300 \mathrm{mg} / \mathrm{kg}$ ) or its vehicle was administered $30 \mathrm{~min}$ before the morphine-priming injection and reinstatement test (morphine was administered immediately before the reinstatement test session). We also examined the involvement of mGlu2/3 receptors in the anti-reinstatement effects of modafinil by administering the mGlu2/3 receptor antagonist LY341495 $(3 \mathrm{mg} / \mathrm{kg}) 30 \mathrm{~min}$ before the modafinil injection preceding the morphine-prime reinstatement test. Finally, in Experiment 4, the effects of modafinil on expression of CPP and on the cueing properties of 


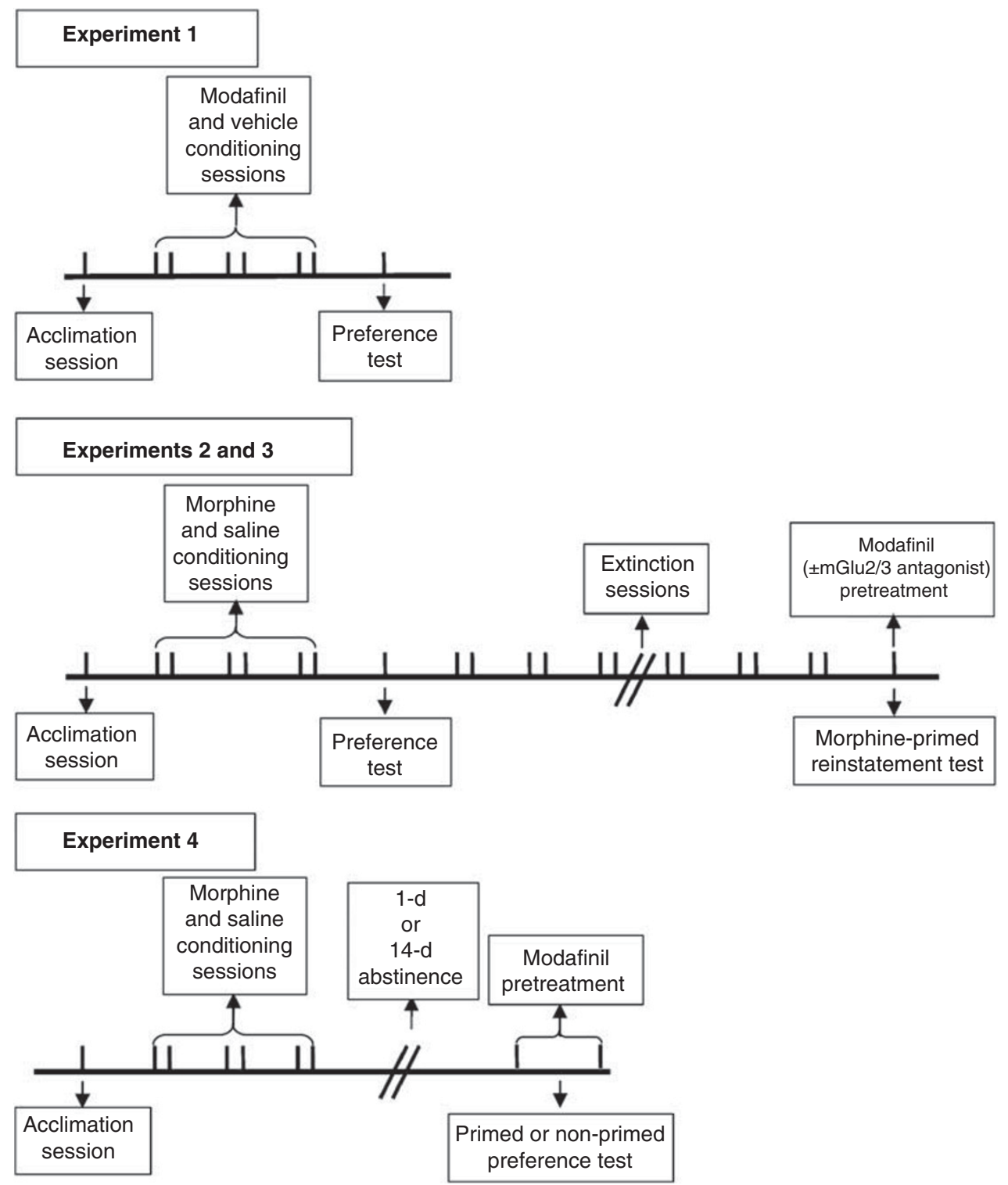

Figure I Experimental design. In Experiment I (upper panel), rats were trained to associate an environment with modafinil using the conditioned place preference (CPP) procedure, and preference was tested $24 \mathrm{~h}$ after the last conditioning session. In Experiments 2 and 3 (middle panel), following training for morphine CPP, rats underwent extinction training. The ability of a morphine prime to reinstate extinguished morphine CPP was tested $24 \mathrm{~h}$ after the last extinction session. The break in the line indicates the variable time required to meet extinction criteria for different animals. In Experiment 4 (lower panel), rats were trained for morphine CPP and the effect of modafinil on the expression of morphine CPP was tested either I day or I4 days after the last conditioning session (either in the presence or absence of a morphine prime). Vertical lines represent days. The break in the line indicates the I day or I 4 days of abstinence before the expression test. Please refer to 'Materials and Methods' for a detailed description of each experiment.

morphine were tested either $24 \mathrm{~h}$ or 14 days after morphine CPP conditioning. Modafinil $(300 \mathrm{mg} / \mathrm{kg})$ or its vehicle was injected $30 \mathrm{~min}$ before the preference test either in the presence or absence of a priming injection of morphine $(8 \mathrm{mg} / \mathrm{kg})$.

\section{Data Analyses}

Preference scores were calculated as the time spent in the drug-paired compartment minus time spent in the vehiclepaired compartment on the post-conditioning preference test days, including extinction and reinstatement trials. All results are represented as mean \pm SEM. Data were assessed by paired and independent $t$-tests, or one- or two-way
ANOVAs. Whenever necessary, post hoc analyses were carried out with Tukey-Kramer's multiple comparison tests. $P$-values $<0.05$ were considered significant. Calculations were performed using the SPSS statistical package (version 17).

\section{RESULTS}

In Experiment 1, we found that pairing modafinil $(300 \mathrm{mg} /$ $\mathrm{kg}$ ) with one compartment produced neither a preference nor an aversion toward the modafinil-paired side (preference score $=0 \pm 49 \mathrm{~s}$ ) compared with the acclimation session (preconditioning; preference score $=-26 \pm 30 \mathrm{~s}$; paired-sample $t$-test, $t(15)=-0.557, p=0.595$; data not 


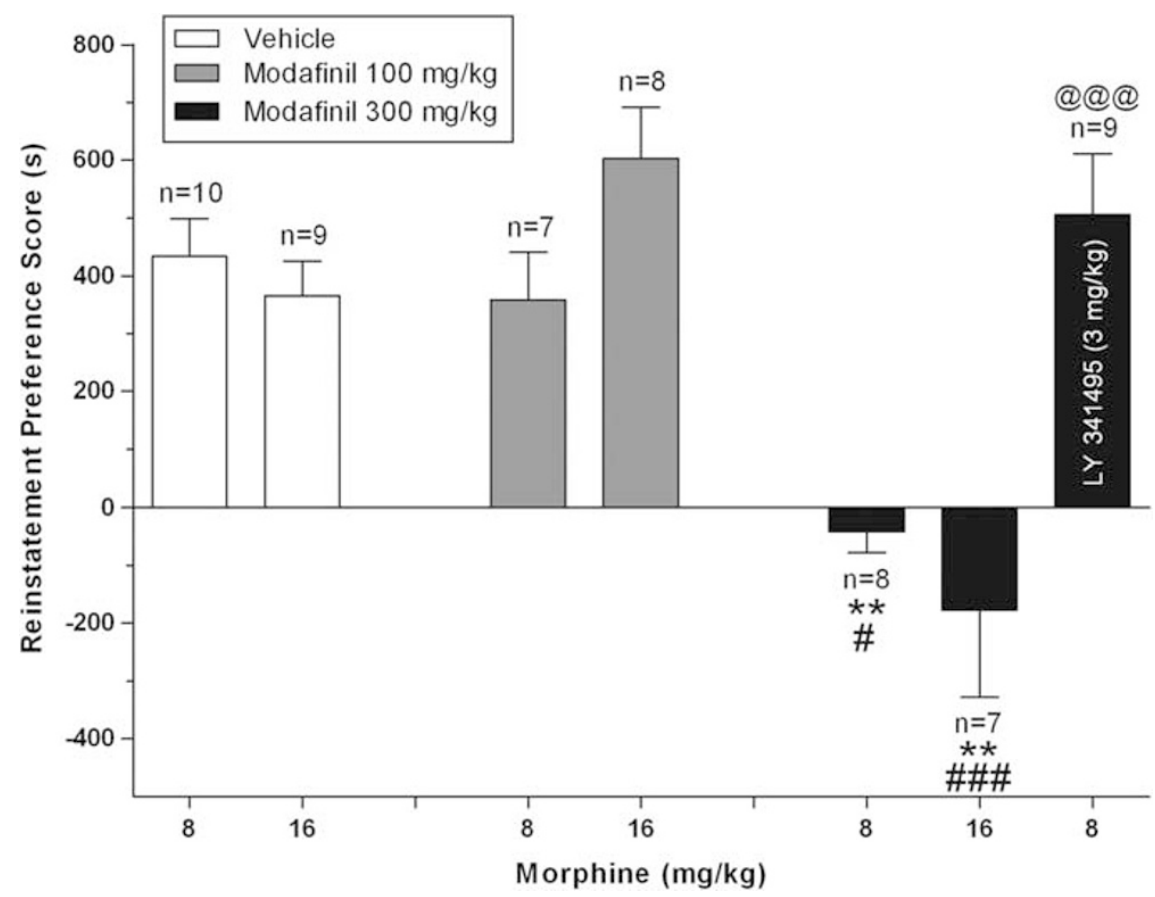

Figure 2 Modafinil pretreatment blocks reinstatement of morphine conditioned place preference (CPP) and mGlu2/3 receptor blockade prevents the antirelapse effects of modafinil. Following acquisition of CPP, animals were exposed to daily extinction training. On the reinstatement test day, rats received modafinil ( 100 or $300 \mathrm{mg} / \mathrm{kg}$, i.p.), or its vehicle, $30 \mathrm{~min}$ before a priming injection of morphine ( 8 or $16 \mathrm{mg} / \mathrm{kg}$, i.p.). In a separate group of animals, the mGlu2/3R antagonist LY34 I 495 (right bar) was injected 30 min before modafinil (300 mg/kg) administration. Reinstatement was tested immediately after the morphine-priming injection in all cases. Preference scores ((time spent in the morphine-paired side)-(time spent in saline-paired side)) for the reinstatement test are expressed as mean \pm SEM. Data shown here represent results of reinstatement tests only. $* * * 0.01$ different from corresponding vehiclepretreated group; ${ }^{\#}$ and $\# \# \#<0.05$ and $p<0.001$ different from the corresponding group pretreated with modafinil (I00 mg/kg), respectively. ${ }_{0} @_{p}<0.00$ I different from the control modafinil $300 \mathrm{mg} / \mathrm{kg}+$ morphine $8 \mathrm{mg} / \mathrm{kg}$ group; there was no significant difference between the LY34I495 + modafinil $300 \mathrm{mg} / \mathrm{kg}+$ morphine $8 \mathrm{mg} / \mathrm{kg}$ group and the morphine $8 \mathrm{mg} / \mathrm{kg}$ control group.

shown). This revealed that modafinil alone did not have a reward valence in this paradigm, consistent with previous reports indicating its low abuse potential (DerocheGamonet et al, 2002; Myrick et al, 2004).

In Experiment 2, animals conditioned with morphine $(8 \mathrm{mg} / \mathrm{kg})$ showed a significant preference for the morphinepaired side on the post-conditioning day (preference score $=281 \pm 34 \mathrm{~s}$; $t$-test, $t(43)=-9.786, p<0.001$; data not shown). Conditioned preference was then extinguished by repeated exposure to both morphine- and saline-paired compartments without any drug injection (last extinction session preference score for morphine-paired side$-51 \pm 15 \mathrm{~s}$ ). Figure 2 shows the effect of modafinil on reinstatement of morphine CPP. A morphine-priming injection $24 \mathrm{~h}$ after the last extinction session reinstated $\mathrm{CPP}$, but modafinil pretreatment significantly blocked that reinstatement (two-way ANOVA; factor modafinil: $\mathrm{F}_{2,43}=28.147$ and $p<0.001$; factor morphine: $\mathrm{F}_{1,43}=0.039$ and $p=0.844$; factor modafinil $\times$ morphine: $\mathrm{F}_{2,43}=2.799$ and $p=0.079$ ). Further analyses by Tukey-Kramer's multiple comparison tests on the main effect of modafinil dose revealed that pretreatment with modafinil $300 \mathrm{mg} / \mathrm{kg}$, but not $100 \mathrm{mg} / \mathrm{kg}, 30 \mathrm{~min}$ before the morphine-priming injection $(8$ or $16 \mathrm{mg} / \mathrm{kg}$ ) completely blocked the reinstatement of morphine preference compared with vehicle-pretreated animals. Modafinil $300 \mathrm{mg} / \mathrm{kg}$ in the absence of a morphinepriming injection ( $30 \mathrm{~min}$ before saline injection) did not produce a significant change in preference (preference score $=28 \pm 98 \mathrm{~s}$; data not shown) compared with the preconditioning (preference score $=-63 \pm 49 \mathrm{~s}$; pairedsample $t$-test, $t(9)=0.745, p>0.05)$ or extinction sessions (preference score $=-176 \pm 50 \mathrm{~s}$; paired-sample $t$-test, $t(9)=2.055, p>0.05)$. A one-way ANOVA showed that reinstatement treatment groups were not different from each other on preconditioning $\left(\mathrm{F}_{5,37}=0.408\right.$ and $\left.p=0.840\right)$, post-conditioning $\left(\mathrm{F}_{5,37}=1.506\right.$ and $\left.p=0.212\right)$, or the last three extinction tests $\left(\mathrm{F}_{5,37}=1.193\right.$ and $\left.p=0.328\right)$.

To test whether modafinil blocks reinstatement by increasing glutamate release that then binds to mGlu2/ $3 R s$, we examined the ability of the mGlu2/3R antagonist LY341495 to interfere with modafinil's ability to block reinstatement of morphine-seeking in another group of rats. As shown in Figure 2, we found that LY341495 $(3 \mathrm{mg} / \mathrm{kg}$ ) administered $30 \mathrm{~min}$ before modafinil completely prevented the anti-reinstatement effects of modafinil ( $t$-test, $t(15)=4.645, p=0.001)$. In contrast, pretreatment with LY341495 $(3 \mathrm{mg} / \mathrm{kg})$ in the absence of a morphine prime (30 and $60 \mathrm{~min}$ before injections of vehicles for both morphine and modafinil) did not cause reinstatement of morphine CPP. Analyses of these reinstatement-control groups revealed that preference toward the morphine-paired side on the reinstatement trial (preference score $=-54 \pm 66 \mathrm{~s}$ ) was not significantly different from that in the preconditioning (preference score $=-31 \pm 23 \mathrm{~s}$; paired-samples $t$-test, $t(6)=-0.922, p=0.392)$ or last extinction test (preference score $=-48 \pm 58 \mathrm{~s}$; paired-samples $t$-test, $t(6)=-0.846, p=0.436)$, but was different from the postconditioning test (before commencement of extinction 


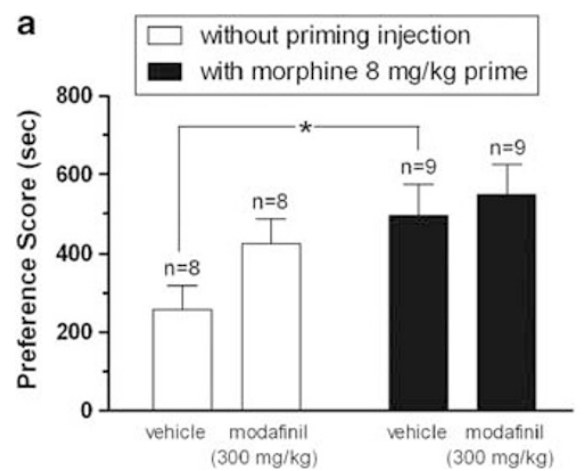

b

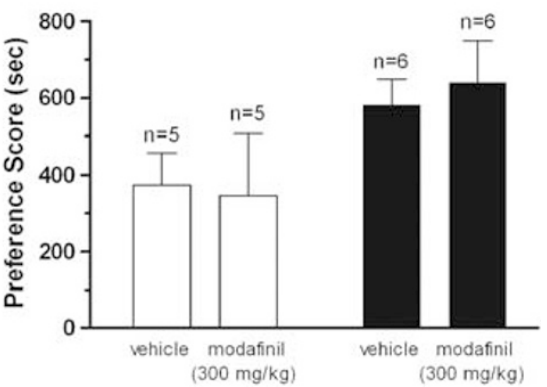

Figure 3 Modafinil pretreatment does not alter primed nor nonprimed expression of morphine-induced place preference. All animals were conditioned with morphine $(8 \mathrm{mg} / \mathrm{kg})$ in a 3-day schedule as described in 'Materials and Methods'. Either I day (a) or 14 days (b) after the last conditioning session, modafinil $(300 \mathrm{mg} / \mathrm{kg})$ or its vehicle $(4 \mathrm{ml} / \mathrm{kg}$ ) was injected $30 \mathrm{~min}$ before the test session in the presence (black bars) or absence (white bars) of a morphine prime. There was no extinction training in any of these animals. Preference scores ((time spent in the morphine-paired side)-(time spent in saline-paired side)) are expressed as mean \pm SEM. The morphine prime increased preference as expected. All groups expressed significant morphine CPP that was not altered by modafinil pretreatment. $* P<0.05$.

training without any injections) as expected $(246.8 \pm 43.1 \mathrm{~s}$; paired-samples $t$-test, $t(6)=-4.491, p<0.05)$. These results show that animals learned the CPP and extinction, but that LY341495 alone after extinction did not cause reinstatement (data not shown).

In Experiment 3, to test whether anti-reinstatement effects of modafinil require extinction training or may interfere with the memory of the morphine context and/or with cueing effects of morphine, we evaluated modafinil effects on the primed and nonprimed expression of morphine CPP in separate groups of animals. At 1- or 14-day after morphine CPP conditioning, rats were injected with modafinil $300 \mathrm{mg} / \mathrm{kg}$ or vehicle $30 \mathrm{~min}$ before the preference test, and expression of conditioned preference was measured in the presence or absence of a morphinepriming injection given immediately before the preference test (Figure 3). Rats in all groups tested either $24 \mathrm{~h}$ or 14 days after the last conditioning session showed a significant preference for the morphine-paired side in comparison with the saline-paired side. A significant effect of the priming injection of morphine was observed in the expression test, such that primed animals showed greater preference than vehicle pretreated subjects, as expected. Pretreatment with modafinil did not significantly alter the expression of morphine CPP, nor did it affect the ability of a morphine prime to augment preference (two-way ANOVA; 1 day after conditioning, factor morphine: $F_{1,30}=6.282$ and $p=0.018$, factor modafinil: $\mathrm{F}_{1,30}=2.373$ and $p=0.134$, factor modafinil $\times$ morphine: $\mathrm{F}_{1,30}=0.607$ and $p=0.442$; 14 days after conditioning, factor morphine: $F_{1,18}=5.337$ and $p=0.033$, factor modafinil: $\mathrm{F}_{1,18}=0.021$ and $p=0.885$, factor modafinil $\times$ morphine: $\mathrm{F}_{1,18}=0.153$ and $p=0.701$ ). These data indicate that the reinstatement-blocking effect of modafinil is selective for drug-induced reinstatement of morphine CPP following extinction training, and is not attributable to interference with contextual memory or suppression of cueing properties of morphine.

\section{DISCUSSION}

In this study, we found that acute modafinil pretreatment blocks reinstatement of extinguished morphine CPP, in an animal model of relapse to opiate abuse. We also showed that this anti-reinstatement effect required stimulation of mGlu2/3Rs. However, modafinil did not affect expression of morphine reward following a short or long delay after conditioning, nor alter cueing properties of morphine. Therefore, this effect appears to be specific to reinstatement of extinguished preference.

The most challenging problem in the treatment of addictive disorders is prevention of relapse to drugtaking/seeking following abstinence (O’Brien, 1997). For more than three decades, the primary long-term treatment for opiate dependence has been extended detoxification and substitution with opiate agonists such as methadone, LAAM, or buprenorphine. These treatments, however, have limited and short-term effectiveness, and only attenuate withdrawal symptoms rather than curing the underlying disorder. Opiate agonists are sedative, cause respiratory depression that can be fatal, and have their own addictive potential. In addition, their long-term use may result in adaptive changes in brain that could contribute to withdrawal reactions and relapse. The use of opiate antagonists, although theoretically effective, is limited in practice to patients with strong motivation for treatment (Nutt and Lingford-Hughes, 2008). Therefore, better relapse-prevention agents with a narrow spectrum of side effects that can alter the brain changes related to addiction, and do not have abuse potential, are needed for opiate addicts.

Reexposure to a drug of abuse, including an opiate, serves as a powerful stimulus for driving relapse to drug-seeking behavior (de Wit and Stewart, 1983; Jaffe et al, 1989; Stewart, 1983). We used the CPP paradigm to test modafinil's ability to facilitate abstinence from opiate abuse in the face of a morphine prime. CPP measures conditioned approach to stimuli/contexts previously associated with drugs (Bardo and Bevins, 2000), and has been repeatedly shown to be effective for testing reinstatement of extinguished preference for contexts associated with various drugs of abuse including opiates and stimulants; in these tests, preference can be reinstated upon reexposure to drug or stressors, as in self-administration paradigms (Aguilar et al, 2009; Shaham et al, 2003). Thus, reinstatement of extinguished drug preference with the CPP paradigm is an effective means of testing relapse liability in response to 
common challenges faced by the addict. In this study, we have shown for the first time that modafinil is capable of blocking the reinstatement of previously extinguished morphine place conditioning. This adds to previous clinical data suggesting that modafinil is effective for treating cocaine addiction (Anderson et al, 2009; Dackis et al, 2005; Hart et al, 2008).

A major goal in the search for new pharmacotherapies for addiction is to find treatments that are devoid of side effects and abuse potential. We found that modafinil is not rewarding by itself as measured by induction of place preference, in line with previous findings (DerocheGamonet et al, 2002). It has been reported that modafinil can act as a reinforcer similar to stimulant drugs (Stoops et al, 2005) and modafinil's effects in increasing alerting and performance are comparable to D-amphetamine (Makris et al, 2007). But, in general, clinical studies have reported a low abuse liability for modafinil (Myrick et al, 2004). Also, modafinil's pharmacokinetic profile makes it unfavorable for being abused (Martinez-Raga et al, 2008). Although it has been shown that modafinil reduces craving for cocaine (Hart et al, 2008), a recent preclinical study reported that modafinil $(128 \mathrm{mg} / \mathrm{kg})$ alone can reinstate an extinguished CPP for cocaine (Bernardi et al, 2009); note, though, that the effects of modafinil pretreatment on reinstatement induced by a priming injection of cocaine have not been investigated. Modafinil does not impair inhibitory control (Vansickel et al, 2008), and in spite of producing mild cardiovascular effects, it has an acceptable side-effect profile, no clinically significant drug interactions, and is well tolerated (Hellriegel et al, 2001; Wong et al, 1999), making it an attractive therapeutic option.

Although reexposure to drugs is a potent factor in triggering relapse, several other factors such as stressors and contextual or discrete cues previously associated with drug use can also cause relapse to drug-seeking in the absence of drug of abuse (Shalev et al, 2002). Several lines of evidence indicate major differences in the underlying neurocircuitry of relapse induced by drugs, cues, and stressors (Bossert et al, 2005b; Shaham et al, 2003). This may result in differential effects of a potential treatment on drug- $v s$ cue-induced reinstatement of drug-seeking. Possible effects of modafinil on cue- and stress-induced reinstatement of drug-seeking were not investigated here, but warrant further investigation. In addition, recent findings indicate that modafinil increases dopamine availability in nucleus accumbens (Volkow et al, 2009). In our study, modafinil blocked morphine-primed reinstatement of CPP. Although the role of dopamine in drug-primed reinstatement of opiate CPP is controversial (Aguilar et al, 2009), an increase in dopamine release in general is expected to cause or facilitate reinstatement, but is very unlikely to block reinstatement. Therefore, the antireinstatement effects of modafinil observed in our study are unlikely to be mediated by an increase in dopamine release.

Glutamatergic transmission has a pivotal role in relapse to addiction for different drugs of abuse including cocaine and heroin. Enhanced synaptic release of glutamate from terminals of prefrontal cortex neurons following reexposure to drugs of abuse, drug-associated cues, or stress provokes reinstatement of drug-seeking (Knackstedt and Kalivas,
2009). This enhanced synaptic glutamate release is proposed to be caused by reduced basal levels of extracellular, nonsynaptic glutamate in the nucleus accumbens that occur with chronic drug exposure (Knackstedt and Kalivas, 2009). Therefore, restoration of basal glutamate levels during abstinence, or blockade of prelimbic cortex glutamatergic projections to the nucleus accumbens, are major potential targets in relapse prevention. Accordingly, inhibition of AMPA/kainite receptors in nucleus accumbens core reduces drug- and cue-induced reinstatement of heroin-seeking (LaLumiere and Kalivas, 2008). However, extracellular glutamate can also bind to a distinct group of metabotropic glutamate receptors (mGluRs) that mediate slow, modulatory glutamatergic transmission. Activation of presynaptically localized mGlu2/3Rs dampens synaptic release of glutamate (Gass and Olive, 2008) and thereby could prevent relapse to drug-seeking. Activation of $m$ GluR2/3 receptors has been shown to inhibit reinstatement of drug-seeking for several drugs. For instance, it has been shown that systemic, intrategmental or intraaccumbens administration of mGlu2/ $3 \mathrm{R}$ agonists inhibits cue- or context-induced reinstatement of extinguished heroin-seeking (Bossert et al, 2005a, 2006, 2004).

Modafinil has been shown to increase extracellular levels of glutamate in various brain regions (Ferraro et al, 1997, 1998, 1999, 1996; Perez de la Mora et al, 1999). However, only a high dose $(300 \mathrm{mg} / \mathrm{kg})$ of modafinil increases striatal glutamate release (134 $\pm 11 \%$ of basal level) (Ferraro et al, 1998). Our data show that only the higher dose of modafinil $(300 \mathrm{mg} / \mathrm{kg}$ ) used in this study is able to block reinstatement of morphine CPP. Importantly, this anti-reinstatement effect of modafinil was fully suppressed by the selective mGlu2/3R antagonist LY 341495. In view of this and other evidence noted above that stimulation of mGlu2/3Rs decreases reinstatement of drug-seeking in other paradigms, we hypothesize that modafinil predominantly increases extrasynaptic glutamate (in areas such as nucleus accumbens) and preferentially stimulates extrasynaptic mGlu2/3Rs. The glutamate released by modafinil may also activate ionotropic (synaptic) glutamate receptors, or other extrasynaptic receptors (such as mGlu1/5 receptors). However, activation of these receptors-as opposed to mGlu2/3 receptors - would be expected to cause, rather than block, reinstatement behavior. Therefore, our behavioral findings suggest that the net effect of modafinil results from activation of mGlu2/3Rs. In support of this view, recent findings show that extinction training causes a downregulation of $\mathrm{mGlu} 1 / 5$ receptors in the nucleus accumbens through elevation of Homerlb/c (Knackstedt et al, 2010). A similar downregulation of mGlu1/5Rs in our animals that were subjected to extinction training may be an important factor that allows extrasynaptic glutamate released by modafinil to preferentially act on mGlu2/3 receptors rather than $\mathrm{mGlu} 1 / 5$ receptors.

It is notable that modafinil had no effect on morphine preference in animals that were not subjected to extinction training, despite being tested at a similar time after conditioning as extinguished animals. Thus, extinction training is needed for the beneficial effects of modafinil to blunt morphine preference. This may result, at least in part, from the downregulation of extrasynaptic mGlu1/5Rs caused by extinction, and supports our hypothesis that 
modafinil is acting primarily at extrasynaptic mGlu2/3Rs to decrease reinstatement in our studies. The exact mechanism of interaction between modafinil and glutamate receptors warrants further investigation.

Interestingly, the lower dose of modafinil $(100 \mathrm{mg} / \mathrm{kg})$, especially in combination with a higher priming dose of morphine $(16 \mathrm{mg} / \mathrm{kg})$, showed a trend toward enhancing reinstatement (although it did not reach statistical significance; Figure 1, middle bars). This highlights the point that subthreshold doses of modafinil not only may not prevent relapse, but may also provoke relapse in some instances such as exposure to high doses of drug of abuse.

It has been reported that modafinil alters locomotor activity in rats (Ishizuka et al, 2008). In our study, modafinil did not affect locomotor activity measured during preference tests; however, it is possible that further assessment may reveal some effects of modafinil on aspects of locomotion.

In conclusion, these results reveal for the first time that modafinil blocks reinstatement of extinguished morphine preference, and that behavioral effects of this drug may involve an mGlu2/3R mechanism. These findings indicate that modafinil may be a new preventive therapy for opiate dependence relapse in human addicts although this has to be approached cautiously.

\section{ACKNOWLEDGEMENTS}

This study was supported by PHS Grants R01 DA017289, R37 DA06214, and P50 DA015369. We thank Cephalon for generously supplying the modafinil used in this study. We also thank Dr Peter Kalivas, Dr Rachel Smith, and Dr Stephen Mahler for helpful suggestions and comments on an initial draft of this article; Dr Charles O'Brien for early encouragement to conduct such studies; and Becky Fallon and Kristen Murray for technical assistance.

\section{DISCLOSURE}

In the past 3 years GA-J received compensation from Lilly Pharmaceuticals, Lundbeck Pharmaceuticals, Sanofi Aventis Pharmaceuticals, and Jazz Pharmaceuticals. None of these present a conflict for the present report. The other authors declare that they do not have any potential conflict of interest or sources of to disclose.

\section{REFERENCES}

Aguilar MA, Rodriguez-Arias M, Minarro J (2009). Neurobiological mechanisms of the reinstatement of drug-conditioned place preference. Brain Res Rev 59: 253-277.

Anderson AL, Reid MS, Li SH, Holmes T, Shemanski L, Slee A et al (2009). Modafinil for the treatment of cocaine dependence. Drug Alcohol Depend 104: 133-139.

Bardo MT, Bevins RA (2000). Conditioned place preference: what does it add to our preclinical understanding of drug reward? Psychopharmacology (Berl) 153: 31-43.

Bernardi RE, Lewis JR, Lattal KM, Berger SP (2009). Modafinil reinstates a cocaine conditioned place preference following extinction in rats. Behav Brain Res 204: 250-253.
Bossert JM, Busch RF, Gray SM (2005a). The novel mGluR2/3 agonist LY379268 attenuates cue-induced reinstatement of heroin seeking. Neuroreport 16: 1013-1016.

Bossert JM, Ghitza UE, Lu L, Epstein DH, Shaham Y (2005b). Neurobiology of relapse to heroin and cocaine seeking: an update and clinical implications. Eur J Pharmacol 526: 36-50.

Bossert JM, Gray SM, Lu L, Shaham Y (2006). Activation of group II metabotropic glutamate receptors in the nucleus accumbens shell attenuates context-induced relapse to heroin seeking. Neuropsychopharmacology 31: 2197-2209.

Bossert JM, Liu SY, Lu L, Shaham Y (2004). A role of ventral tegmental area glutamate in contextual cue-induced relapse to heroin seeking. J Neurosci 24: 10726-10730.

Dackis CA, Kampman KM, Lynch KG, Pettinati HM, O’Brien CP (2005). A double-blind, placebo-controlled trial of modafinil for cocaine dependence. Neuropsychopharmacology 30: 205-211.

de Wit H, Stewart J (1983). Drug reinstatement of heroinreinforced responding in the rat. Psychopharmacology (Berl) 79: $29-31$.

Deroche-Gamonet V, Darnaudery M, Bruins-Slot L, Piat F, Le Moal M, Piazza PV (2002). Study of the addictive potential of modafinil in naive and cocaine-experienced rats. Psychopharmacology (Berl) 161: 387-395.

Ferraro L, Antonelli T, O'Connor WT, Tanganelli S, Rambert F, Fuxe K (1997). The antinarcoleptic drug modafinil increases glutamate release in thalamic areas and hippocampus. Neuroreport 8: 2883-2887.

Ferraro L, Antonelli T, O'Connor WT, Tanganelli S, Rambert FA, Fuxe K (1998). The effects of modafinil on striatal, pallidal and nigral GABA and glutamate release in the conscious rat: evidence for a preferential inhibition of striato-pallidal GABA transmission. Neurosci Lett 253: 135-138.

Ferraro L, Antonelli T, Tanganelli S, O'Connor WT, Perez de la Mora M, Mendez-Franco J et al (1999). The vigilance promoting drug modafinil increases extracellular glutamate levels in the medial preoptic area and the posterior hypothalamus of the conscious rat: prevention by local GABAA receptor blockade. Neuropsychopharmacology 20: 346-356.

Ferraro L, Tanganelli S, O'Connor WT, Antonelli T, Rambert F, Fuxe K (1996). The vigilance promoting drug modafinil decreases GABA release in the medial preoptic area and in the posterior hypothalamus of the awake rat: possible involvement of the serotonergic 5-HT3 receptor. Neurosci Lett 220: $5-8$.

Gass JT, Olive MF (2008). Glutamatergic substrates of drug addiction and alcoholism. Biochem Pharmacol 75: 218-265.

Harris GC, Aston-Jones G (2003a). Altered motivation and learning following opiate withdrawal: evidence for prolonged dysregulation of reward processing. Neuropsychopharmacology 28: 865-871.

Harris GC, Aston-Jones G (2003b). Enhanced morphine preference following prolonged abstinence: association with increased Fos expression in the extended amygdala. Neuropsychopharmacology 28: $292-299$.

Harris GC, Wimmer M, Aston-Jones G (2005). A role for lateral hypothalamic orexin neurons in reward seeking. Nature 437: 556-559.

Hart CL, Haney M, Vosburg SK, Rubin E, Foltin RW (2008). Smoked cocaine self-administration is decreased by modafinil. Neuropsychopharmacology 33: 761-768.

Hellriegel ET, Arora S, Nelson M, Robertson Jr P (2001). Steadystate pharmacokinetics and tolerability of modafinil given alone or in combination with methylphenidate in healthy volunteers. J Clin Pharmacol 41: 895-904.

Ishizuka T, Murakami M, Yamatodani A (2008). Involvement of central histaminergic systems in modafinil-induced but not methylphenidate-induced increases in locomotor activity in rats. Eur J Pharmacol 578: 209-215. 
Jaffe JH, Cascella NG, Kumor KM, Sherer MA (1989). Cocaineinduced cocaine craving. Psychopharmacology (Berl) 97: 59-64.

Knackstedt LA, Kalivas PW (2009). Glutamate and reinstatement. Curr Opin Pharmacol 9: 59-64.

Knackstedt LA, Moussawi K, Lalumiere R, Schwendt M, Klugmann M, Kalivas P (2010). Extinction training after cocaine selfadministration induces glutamatergic plasticity to inhibit cocaine seeking. J Neurosci 30: 7984-7992.

LaLumiere RT, Kalivas PW (2008). Glutamate release in the nucleus accumbens core is necessary for heroin seeking. J Neurosci 28: 3170-3177.

Makris AP, Rush CR, Frederich RC, Taylor AC, Kelly TH (2007). Behavioral and subjective effects of D-amphetamine and modafinil in healthy adults. Exp Clin Psychopharmacol 15: 123-133.

Malcolm R, Swayngim K, Donovan JL, DeVane CL, Elkashef A, Chiang $\mathrm{N}$ et al (2006). Modafinil and cocaine interactions. Am J Drug Alcohol Abuse 32: 577-587.

Markou A (2007). The role of metabotropic glutamate receptors in drug reward, motivation and dependence. Drug News Perspect 20: 103-108.

Martinez-Raga J, Knecht C, Cepeda S (2008). Modafinil: a useful medication for cocaine addiction? Review of the evidence from neuropharmacological, experimental and clinical studies. Curr Drug Abuse Rev 1: 213-221.

Minzenberg MJ, Carter CS (2008). Modafinil: a review of neurochemical actions and effects on cognition. Neuropsychopharmacology 33: 1477-1502.

Moran MM, McFarland K, Melendez RI, Kalivas PW, Seamans JK (2005). Cystine/glutamate exchange regulates metabotropic glutamate receptor presynaptic inhibition of excitatory transmission and vulnerability to cocaine seeking. J Neurosci 25: 6389-6393.

Myrick H, Malcolm R, Taylor B, LaRowe S (2004). Modafinil: preclinical, clinical, and post-marketing surveillance-a review of abuse liability issues. Ann Clin Psychiatry 16: 101-109.
Nutt D, Lingford-Hughes A (2008). Addiction: the clinical interface. Br J Pharmacol 154: 397-405.

O'Brien CP (1997). A range of research-based pharmacotherapies for addiction. Science 278: 66-70.

Perez de la Mora M, Aguilar-Garcia A, Ramon-Frias T, RamirezRamirez R, Mendez-Franco J, Rambert F et al (1999). Effects of the vigilance promoting drug modafinil on the synthesis of GABA and glutamate in slices of rat hypothalamus. Neurosci Lett 259: 181-185.

Shaham Y, Shalev U, Lu L, De Wit H, Stewart J (2003). The reinstatement model of drug relapse: history, methodology and major findings. Psychopharmacology (Berl) 168: 3-20.

Shalev U, Grimm JW, Shaham Y (2002). Neurobiology of relapse to heroin and cocaine seeking: a review. Pharmacol Rev 54: $1-42$.

Stewart J (1983). Conditioned and unconditioned drug effects in relapse to opiate and stimulant drug self-adminstration. Prog Neuropsychopharmacol Biol Psychiatry 7: 591-597.

Stoops WW, Lile JA, Fillmore MT, Glaser PE, Rush CR (2005). Reinforcing effects of modafinil: influence of dose and behavioral demands following drug administration. Psychopharmacology (Berl) 182: 186-193.

Vansickel AR, Fillmorex MT, Hays LR, Rush CR (2008). Effects of potential agonist-replacement therapies for stimulant dependence on inhibitory control in cocaine abusers. Am J Drug Alcohol Abuse 34: 293-305.

Volkow ND, Fowler JS, Logan J, Alexoff D, Zhu W, Telang F et al (2009). Effects of modafinil on dopamine and dopamine transporters in the male human brain: clinical implications. JAMA 301: 1148-1154.

Wong YN, Simcoe D, Hartman LN, Laughton WB, King SP, McCormick GC et al (1999). A double-blind, placebo-controlled, ascending-dose evaluation of the pharmacokinetics and tolerability of modafinil tablets in healthy male volunteers. J Clin Pharmacol 39: 30-40. 